\title{
Les « Odysséennes » de Habib Tengour - Petite esquisse généalogique
}

\section{Regina Keil-Sagawe}

\section{OpenEdition}

\section{Journals}

Édition électronique

URL : https://journals.openedition.org/coma/6521

DOI : 10.4000/coma.6521

ISSN : 2275-1742

Éditeur

Institut des textes \& manuscrits modernes (ITEM)

\section{Référence électronique}

Regina Keil-Sagawe, "Les « Odysséennes » de Habib Tengour - Petite esquisse généalogique », Continents manuscrits [En ligne], 15 | 2020, mis en ligne le 20 octobre 2020, consulté le 13 janvier 2023. URL : http://journals.openedition.org/coma/6521 ; DOI : https://doi.org/10.4000/coma.6521

Ce document a été généré automatiquement le 13 janvier 2023.

\section{(c) $(1) \&$}

Creative Commons - Attribution - Pas d'Utilisation Commerciale - Pas de Modification 4.0 International - CC BY-NC-ND 4.0

https://creativecommons.org/licenses/by-nc-nd/4.0/ 


\title{
Les « Odysséennes » de Habib Tengour - Petite esquisse généalogique
}

\author{
Regina Keil-Sagawe
}

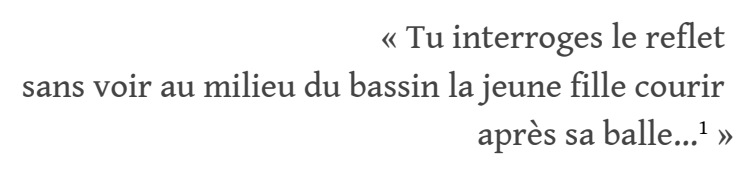

1 C'est ainsi que se termine "L'île au loin », poème-prélude aux Odysséennes tengouriennes, composé au lendemain d'un 8 mars, le 9 mars 2003 pour tout dire. Habib Tengour s'est-il douté à ce moment-là que la jeune fille en question, Nausicaa, allait bientôt sortir des limbes de la perception d'Ulysse/alter ego de l'auteur, pour s'installer de plein droit dans une galerie de portraits féminins inspirés par l'Odyssée ?

2 J'en doute... On connaît, bien évidemment, l'engouement du poète algérien, né en 1947 à Mostaganem, cité maritime, pour l'odyssée ; on sait qu'il adore refléter les vécus maghrébins sur fonds homérien ${ }^{2}$, et ceci dès son premier recueil, Tapapakitaques (1976)³, qui débute d'emblée : «Je m'appelle ULYSSE j'ai vingt-deux ans je fais de la sociologie parce que j'ai échoué en Droit ${ }^{4}$. » On connaît la prédilection de Tengour pour le cinéma hollywoodien, l'impact des péplums sur l'imaginaire du garçon", la "cinécriture" de l'adulte ${ }^{6}$, à commencer par Ulysses (1955), le fameux film de Mario Camerini, avec Kirk Douglas comme Ulysses et Silvana Mangano ${ }^{7}$ incorporant à la fois Pénélope et Circé.

3 Mais de là à imaginer Habib Tengour dont l'œuvre intégrale focalisait sur des protagonistes masculins, s'aventurer à concevoir une série intégrale de portraits féminins tirés de l'odyssée, en retravaillant, à sa manière, le mythe?

Il se peut très bien que toutes les remarques concernant l'absence des femmes dans mon écriture m'aient quelque peu contrarié et que j'aie voulu montrer qu'il n'en est rien. Mais cela va au-delà d'un agacement ${ }^{8}$.

4 Ainsi Tengour dans un entretien avec l'auteure de ces lignes en 2012, lors de la publication du sixième poème du premier cycle des Odysséennes, qui n'allait pas dépasser, dans un manuscrit datant de 2010, les huit poèmes. 
5 En effet, dès 2003 Tengour avait commencé à secréter, par-ci, par-là, des poèmes épars, inspirés par Calypso, Circé, Hélène, Hécube, Pénélope, Cassandre et finalement Nausicaa9.

6 Et qui allaient paraître progressivement dans différentes revues littéraires ; d'abord, en 2003, «Calypso écoute $1^{10}$ » et « Conversations avec Calypso" ${ }^{11}$, suivi, en 2005, par « Le sourire de Circé12 $"$, auquel succédera, en 2007 , un poème consacré à la belle Hélène, «Fugitive et ravie ${ }^{13}$ », puis, en 2011, « Hécube $^{14}$ » (transformée dans le recueil présent en « Captive flétrie »), suivie, en 2012, par Pénélope, « La plus sage des femmes ${ }^{15}$ » et qui sera rejointe, en 2013, par Cassandre, «Celle qui déparle ${ }^{16}$ » ainsi que, pour clôturer ce premier cycle des Odysséennes, par « La balle de Nausicaa ${ }^{17} »$.

7 Le manuscrit des Odysséennes dans mes archives, qui date de mars 2010, contient, en outre, cinq titres évoquant d'autres figures féminines de l'univers homérien, Athéna ( La déesse aux yeux pers ») comme les Sirènes ("Les sirènes: Divas sans visage »), puis des femmes proches d'Ulysse: "La nourrice: Attentive à soigner ", "La mère : ombre assoiffée », « La servante : Ni pute ni soumise ».

8 Mais il fallait attendre l'an 2019 avec la publication intégrale du recueil présent, Odysséennes/ Odissaiche, traduit et édité par Fabio Scotto, pour voir comment Tengour a bien pu concrétiser ces titres, ainsi que pour découvrir deux ajouts, consacrés à Charybde ( Ogresses ASSASSINS») et Scylla ( Une caverne sombre au milieu») plus deux poèmes, « La pelle à grain » et « Re-souvenir », tenant lieu de prologue/épilogue. Grande est la tentation de lire ces Odysséennes comme une galerie de portraits-fantômes d'Algériennes (Pénélope l'épouse résignée d'émigré, Hélène l'intempestive fugueuse, Hécube la mère douloureuse etc.), car l'auteur sème des indices suggérant une lecture côté « Place des Martyrs ». Or, si Tengour ne nie pas les préoccupations du moments, l'Algérie apparaissant en filigrane dans le dit poétique, il met tout de même en garde contre toute lecture réductrice, rappelant qu'il s'agit moins « de coller à la réalité algérienne » que «de dire». Dire l'amour, la nostalgie, la peine, "des émotions cristallisées dans la mémoire et que l'événement fait affleurer subtilement à la surface. » Ce qui inclut, comme toujours chez Tengour, de "s'interroger sur les modalités du dire »...

10 Et, comme toujours chez Tengour, ces poèmes se décryptent autant qu'ils se dégustent et vice versa: il y a le jeu de l'intertextualité, bien sûr, avec les classiques et les contemporains de tout bord, et la connaissance du mythe sera bien sûr utile, mais nullement obligatoire. C'est que le poète, en opérant "plusieurs torsions au mythe ", veut « lui rendre son évidence première, celle d'enchanter notre quotidien ${ }^{18}$ ».

11 Ces poèmes - et leur mise en page l'accentue - proposent donc une lecture cadencée, des fragments à méditer, à faire résonner... selon le moment, selon la mémoire, selon chaque lecteur, chaque lectrice, tout au long de l'axe du temps. Le Printemps arabe y résonnera autant que la Décennie noire, la Grèce antique autant que l'Arabie ancienne, les errances méditerranéennes des migrants clandestins de nos jours autant que les catastrophes et cataclysmes à venir, Tengour inscrivant ses Odysséennes au cœur d'un espace d'échos tentaculaires.

12 À noter surtout le renvoi discret aux mou'allaqât, important pour l'ensemble du recueil dont le premier poème jamais publié, "Calypso écoute 1 », commence par un rappel du naçib, la mise en scène classique du poème anté-islamique : 
C'est tremblant de mots qu'au milieu de débris de cendre/ Ulysse fait le point [...] ...

Une trace/ phosphorescence d'un tatouage/ au sortir du songe ${ }^{19}$. donner la peine de comparer attentivement les versions successives des poèmes faisant partie des Odysséennes, constatera, plus d'une fois, que "le travail d'orfèvre ${ }^{20}$ » auquel Tengour s'adonne habituellement, en peaufinant ses poèmes d'une version à l'autre ${ }^{21}$, va ici encore, et malgré des ajouts sporadiques d'un syntagme par-ci, de deux, trois lignes par-là, dans le sens d'une condensation progressive.

C'est tremblant mots au milieu des débris

de cendre/ Ulysse fait le point [...]

... Une trace

Phosphorescence d'un tatouage /

Sortir du songe.

Paillettes micacées d'un lieu-dit évanoui ${ }^{22}$

Condensation-concentration qui fait éclater les connecteurs logiques, pour faire ressortir, de façon d'autant plus saillante, des blocs sémantiques nus, disséminés sur la page... tels des débris, des épaves, des traces... Effet d'explosion ou d'érosion? Mimétisme graphique d'un monde éclaté ? d'une mémoire effondrée ? Écho lointain de ce qui fut et ne sera plus jamais?

Ou bien invitation au voyage, heureux qui comme Ulysse...

$\mathrm{Au}$ lecteur de le découvrir...

\section{NOTES}

1. «L'̂̂le au loin »/ " Die ferne Insel », in Seelenperlmutt, Lyrik französisch-deutsch (traduction et postface par Regina Keil-Sagawe), Berlin, Hans Schiler, 2009, p. 108-113. La première publication du poème remonte à 2003, en bilingue aussi : «L'̂lle au loin»/ «The Far Island», traduction anglaise par Donald Winkler, dans "Miroirs et frontières/Reflections and Borders", La Traductière 21, p. 66-69.

2. Des auteurs comme Salim Bachi, avec Le Chien d'Ulysse (2001), ou Assia Djebar, avec La Femme sans sépulture (2002), suivront, un quart de siècle plus tard, cette piste défrayée par Tengour. Voir aussi Mourad Yelles, Habib Tengour ou l'ancre et la vague: traverses et détours du texte maghrébin, Karthala, Paris, 2003.

3. Habib Tengour, Tapapakitaques - La poésie-île, Paris, Oswald, 1976.

4. Ibid., p. 9.

5. À Tigditt, quartier de la vielle ville de Mostaganem qui a vu grandir Habib Tengour ; cf. aussi Tengour, L'Ancêtre cinéphile, Paris, La Différence, 2010.

6. Cf. Mourad Yelles, «La "cinécriture" de Habib Tengour », dans Les Miroirs de Janus. Littératures orales et écritures postcoloniales (Maghreb-Antilles), Alger, Office des Publications Universitaires, 2002, p. 217-231.

7. Voir le deuil du protagoniste apprenant la mort de l'actrice dans « Ulysse chez les intégristes », une des nouvelles du recueil tengourien Gens de Mosta, Paris/Arles, Actes Sud/Sindbad, 1997. 
8. Habib Tengour dans Regina Keil-Sagawe, « Odysséennes - ou de l'écho féminin dans l'œuvre de Habib Tengour. Sept esquisses pour un entretien », dans Expressions maghrébines 11/1, 2012, «Les écritures nomades de Habib Tengour », dossier coordonné par Sonia Zlitni-Fitouri, p. 117-130 ; ici, p. 119.

9. «L'̂̂le au loin »/ " Die ferne Insel », dans Seelenperlmutt, Lyrik französisch-deutsch (traduction et postface par Regina Keil-Sagawe), Berlin, Hans Schiler, 2009, p. 108-113. La première publication du poème remonte à 2003, en bilingue aussi : "L'île au loin »/ "The Far Island ", traduction anglaise par Donald Winkler, dans "Miroirs et frontières/Reflections and Borders ", La Traductière 21, p. 66-69.

10. Dans Action poétique, $n^{\circ} 174$ (2003), p. 54-56.

11. Dans Europe, $81^{\mathrm{e}}$ année, 2003, $\mathrm{n}^{\circ}$ hors série, «Algérie, littérature et arts », p. 347-351.

12. Dans Autre SUD 30, 2005, p. 66-68.

13. Dans Ponts/Ponti - langues littératures civilisations des pays francophones, $n^{\circ} 7$, «Présences du Mythe ", Bologna, Monduzzi 2007, p. 102-103.

14. Dans Action Poétique 206, 2011, p. 89-93.

15. Dans Expressions maghrébines, $\mathrm{n}^{\circ} 11 / 1$, 2012, "Les écritures nomades de Habib Tengour ", dossier coordonné par Sonia Zlitni-Fitouri, p. 117-130; ici, p. 109-112.

16. Dans Claudia Gronemann et Wilfried Pasqier (éd.), Scènes des genres au Maghreb. Masculinités, critique queer et espaces du féminin/masculin, Amsterdam/ New York, Rodopi, coll. «Francopolyphonies », vol. 11, 2013, p. 230-233.

17. Ibid., p. 334-335.

18. Citations tirées de la petite préface dont Tengour a doté l'édition bilingue Odysséennes/ Odissaiche, p. 4-6; ici, p. 6.

19. Cité d'après la version publiée dans Action poétique, $\mathrm{n}^{\circ} 174,2003$, p. 54-56.

20. . Cf. Mourad Yelles, Habib Tengour, l'arc et la lyre - Dialogues (1988-2004), Alger, Casbah Éditions 2006.

21. Voir, en guise d'exemple, l'étude génétique menée par Hervé Sanson sur différentes versions d'un seul poème tengourien: Hervé Sanson, «Ta voix vit/Nous vivons: la genèse d'un poème d'Habib Tengour à l'aune de ses avant-textes ", Continents manuscrits, $n^{\circ} 5$, 2015, http:// journals.openedition.org/coma/603.

22. «Calypso écoute 1 », dans Odysséennes/ Odissaiche, 2019, p. $16 \mathrm{f}$.

\section{AUTEUR}

\section{REGINA KEIL-SAGAWE}

Professeur en littérature, Heidelberg (Allemagne) 